\title{
The Study of Drought in Future Climate Scenarios in the Huang-Huai-Hai Region
}

\author{
Gengmin Jiang ${ }^{1, *}$, Xiaobo $\mathrm{Gu}^{2}$, Dongsheng Zhao ${ }^{1}$, Jun $\mathrm{Xu}^{1}{ }^{1}$, Changkun Yang ${ }^{1}$, Siyu Wang ${ }^{1}$, Yuying $\mathrm{Li}^{3}$ \\ and Bai-Lian $\mathrm{Li}^{3,4}$ \\ 1 College of Civil Engineering and Architecture, Nanyang Normal University, Nanyang 473061, China; \\ zds123123@yeah.net (D.Z.); xujunhit@126.com (J.X.); YCK36177885@163.com (C.Y.); \\ syla020521@163.com (S.W.) \\ 2 College of Water Resources and Architectural Engineering, Northwest A\&F University, Yangling, \\ Xianyang 712100, China; guxiaobo@nwafu.edu.cn \\ 3 International Joint Laboratory of Watershed Ecological Security for Water Source Region of Middle Route \\ Project of South-North Water Diversion in Henan Province, College of Water Resource and Environment \\ Engineering, Nanyang Normal University, Nanyang 473061, China; lyying200508@163.com (Y.L.); \\ bai-lian.li@ucr.edu (B.-L.L.) \\ 4 Department of Botany and Plant Sciences, University of California, Riverside, CA 92521, USA \\ * Correspondence: jianggengmin2013@126.com
}

check for updates

Citation: Jiang, G.; Gu, X.; Zhao, D.; Xu, J.; Yang, C.; Wang, S.; Li, Y.; Li, B.-L. The Study of Drought in Future Climate Scenarios in the Huang-Huai-Hai Region. Water 2021, 13, 3474. https://doi.org/10.3390/ w13233474

Academic Editor: Yves Tramblay

Received: 25 October 2021

Accepted: 2 December 2021

Published: 6 December 2021

Publisher's Note: MDPI stays neutral with regard to jurisdictional claims in published maps and institutional affiliations.

Copyright: (c) 2021 by the authors. Licensee MDPI, Basel, Switzerland. This article is an open access article distributed under the terms and conditions of the Creative Commons Attribution (CC BY) license (https:/ / creativecommons.org/licenses/by/ $4.0 /)$.

\begin{abstract}
In the context of global warming, agricultural production and social and economic development are significantly affected by drought. The future change of climate conditions is uncertain; thus, it is of great importance to clarify the aspects of drought in order to define local and regional drought adaptation strategies. In this study, the meteorological data from 1976 to 2005 was used as a historical reference, and nine Global Climate Models (GCMs), downscaling to meteorological stations from 2039 to 2089, were used as future climate data. Based on Penman-Monteith, the reference crop Evapotranspiration $\left(\mathrm{ET}_{0}\right)$ and Standardized Precipitation Evapotranspiration Index (SPEI) of the reference crop in three emission scenarios of RCP2.6, RCP4.5, and RCP8.5, under future climate conditions, were calculated. A non-parameter Mann-Kendall trend test was performed on temperature, precipitation, $\mathrm{ET}_{0}$, and SPEI to analyze the drought spatiotemporal distribution traits under upcoming climate scenarios. The results showed that, under future climate conditions, SPEI values in most areas of the Huang-Huai-Hai region would continuously increase year by year, and drought would be alleviated to some extent at the same pace. However, with the increase of greenhouse gas concentration in the emission scenarios, SPEI values continued to decline. In the RCP8.5 scenario, the area of severe drought was large. To sum up, in the future climate scenario, the degree of drought in the Huang-Huai-Hai region will be alleviated to some extent with the increase of rainfall, but with the increase of greenhouse gas concentration, the degree of drought will be further intensified, posing a huge challenge to agricultural water use in the region. This study provides a theoretical foundation for alleviating drought in the Huang-Huai-Hai region in future climate scenarios.
\end{abstract}

Keywords: standardized precipitation evapotranspiration index; evapotranspiration; future climate scenarios

\section{Introduction}

Under the general trend of global warming, extreme climate events occur frequently [1]. The increase of temperature will accelerate water evaporation, causing drought, especially extreme drought, to become one of the most serious environmental issues in the world [2]. According to statistics, the global economic losses caused by drought are as high as USD 6-8 billion every year, severely affecting the sustainable development of global agriculture $[3,4]$. At the same time, drought will also lead to a shortage of water, which will have a consequential impact on water supply and agriculture [5]. Meteorological hazards are the most serious natural disasters affecting agriculture in China, and drought accounts for 
approximately $50 \%$ of these [6,7]. The severe drought in the southwest China from 2009 to 2010 caused huge damage to local agriculture, society, the economy, and the ecological environment [8]. The Huang-Huai-Hai region is one of the largest main grain producing areas in China. There have been several major droughts in this region, including the once-in-a-century drought in 1997, in which $137,000 \mathrm{hm}^{2}$ of summer grain crops dried up and died, and $6700 \mathrm{hm}^{2}$ of farmland failed to yield, severely affecting food safety and ecological balance in the region [9]. Studies suggest that the range of extreme drought may increase from $1 \%$ of the current global area to $30 \%$ by the end of the 21st century [10]. As global warming continues to intensify in the future, the negative impact of drought on food safety and agricultural water management will become more serious. Therefore, it is of a great significance to define the drought characteristics under future climate conditions and suggest reasonable countermeasures [11-14].

Most studies classify drought into five types: meteorological drought, agricultural drought, hydrological drought, socioeconomic drought, and groundwater drought. Meteorological drought is defined as the water deficit caused by the imbalance between total precipitation and surface evaporation in the study area over a certain period. Meteorological drought can lead to other types of droughts. Thus, accurate detection of meteorological drought can effectively prevent and alleviate drought $[15,16]$. Drought index can measure, compare, and analyze the degree of drought, which plays an important role in drought research. Qu et al. [17] examined the spatiotemporal distribution aspects of drought intensity in different regions of Inner Mongolia based on the MCI index. Wei et al. [18] found that the accuracy of $\mathrm{Pa}$, in describing drought intensity, was lower than that of PDSI in most areas of China. Zuo et al. [19] discussed the feasibility of using short-term precipitation series in China to calculate SPI, based on data from 2416 precipitation observation stations during the period 1961-2019. Tang et al. [20] used SPEI and Standardized Runoff Index (SRI), which was developed on the basis of SPI, to analyze the evolution of hydrological and meteorological droughts in southwest China during the period 1968-2018. However, SPI calculation only considers the precipitation impact on drought, disregarding changes caused by the temperature rise. Due to different calculation focuses of various drought indexes, there will be deviations in evaluation results [21]. Yao et al. [22] found that drought severity was mainly affected by evapotranspiration in regions with substantial evapotranspiration changes in Xinjiang, China. SPEI considers, not only precipitation and temperature, but also evapotranspiration changes. Meanwhile, the calculation of SPEI is relatively simple and has more suitable application prospects [23]. Tan et al. [24] used SPEI and SPI to study drought in Ningxia, China, and found that SPEI could describe the drought more accurately. Tirivarombo et al. [25] established that SPEI reflected a more comprehensive drought situation in the Kafue Basin.

The size of potential reference crop evapotranspiration $\left(\mathrm{ET}_{0}\right)$ affects the drought index SPEI. By studying the impacts of precipitation and evapotranspiration on global drought in the 21st century, Cook et al. [26] discovered that the increase of global drought area in the 2080s was mainly due to the increase of $\mathrm{ET}_{0}$. Therefore, it is very important to determine $\mathrm{ET}_{0}$, using appropriate methods to accurately evaluate the drought characteristics. At first, many scholars used the Thornthwaite equation to estimate evapotranspiration when calculating SPEI [27]. The Thornthwaite equation is a method expressing the potential evapotranspiration by temperature, but evapotranspiration is also affected by precipitation, wind speed, humidity, and other factors besides temperature; thus, there will be some deviation when using this equation to assess evapotranspiration [28-30]. In 1990, The Food and Agriculture Organization (FAO) included the Penman-Monteith (PM) equation as the standard calculation for evapotranspiration. This equation is more accurately based on physics, but it considers larger parameters and is more complicated to use [29]. Bae et al. [31] calculated SPEI based on the Thornthwaite and Penman-Monteith equations and conducted comparative analysis. The results indicated that, when the meteorological data were the same, the drought degree calculated using the PM equation was more intense. 
First, this study examined the precipitation and temperature changes in the HuangHuai-Hai region, based on meteorological data in future scenarios, and then calculated the $\mathrm{ET}_{0}$ and SPEI indexes under RCP2.6, RCP4.5, and RCP8.5 scenarios, based on the PM equation, and conducted MK trend tests. Finally, the spatiotemporal distribution and evolution of drought in the Huang-Huai-Hai region were quantified for future scenarios. This study can provide the basis for decision-making on reducing drought risk in the Huang-Huai-Hai region under future meteorological conditions.

\section{Data and Methods}

\subsection{Study Area}

The Huang-Huai-Hai region, located in the east of China, is one of its main grain producing areas. The study area of this article mainly includes Henan, Hebei, Shandong, and Anhui, covering most provinces in the Huang-Huai-Hai region (Figure 1). This location is in the middle latitude zone of the monsoon climate zone in eastern China. In summer (June to August), the long-term mean temperature is $24.6{ }^{\circ} \mathrm{C}$ and the precipitation is $122.9 \mathrm{~mm}$. In winter (December to February), the mean temperature is $2.3^{\circ} \mathrm{C}$ and the precipitation is $9.8 \mathrm{~mm}$. The annual mean temperature and precipitation decreased with the northern and southern latitudes increases [32]. Considering global warming, the climate in the Huang-Huai-Hai region shows a warm and dry trend. The environment of insufficient water resources and increased accumulated temperature has brought many negative effects on local agricultural production.

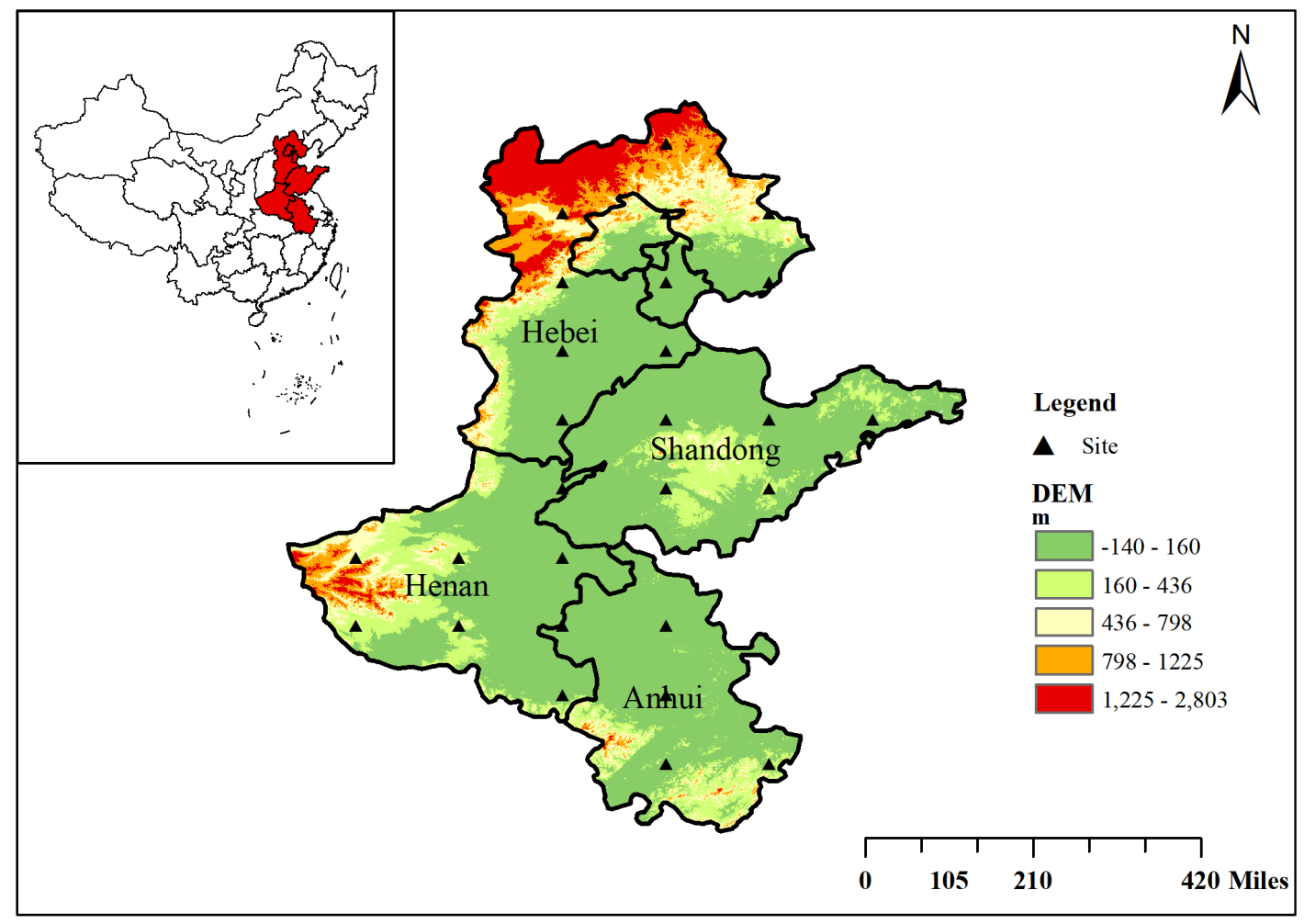

Figure 1. Study area.

\subsection{Data Source}

In this study, the historical reference period is 1976-2005. The daily meteorological data of the Huang-Huai-Hai region were obtained from the China Meteorological Data Website (http:/ / data.cma.cn/en, accessed on 6 October 2021). It mainly includes daily maximum and minimum temperature, near-surface relative humidity, near-surface wind speed, sunlight, and other factors of selected meteorological stations in the study area. Taking 2039-2089 as the study period for future scenarios, the method of downscaling 
was used [33] to obtain the meteorological data of nine climate models (Table 1) in the future, downscaling to station in three emission scenarios (RCP2.6, RCP4.5, and RCP8.5). The RCP is a series of comprehensive concentration and emission scenarios that are used as input parameters of the climate change predictive model, under the influence of 21st century human activities, to describe the emissions of greenhouse gases, reactive gases, and aerosols as well as concentration of atmospheric components under upcoming changes in population, socioeconomics, science and technology, energy consumption, and land use [34-36]. The RCP2.6 represents the total radiative forcing to stabilize at $2.6 \mathrm{Wm}^{-2}$ after 2100 , which is a very low greenhouse gas concentration model. The RCP4.5 represents the total radiative forcing to stabilize at $4.5 \mathrm{Wm}^{-2}$ after 2100 , which is the climate scenario under government intervention. The RCP8.5 represents the total radiative forcing to stabilize at $8.5 \mathrm{Wm}^{-2}$ after 2100, which is a baseline scenario in the absence of climate change policy intervention.

Table 1. Climate models used in this study.

\begin{tabular}{cccc}
\hline No. & Model Name & Institution & Country \\
\hline 1 & CanESM2 & Canadian Centre for Climate Modelling and Analysis & Canada \\
2 & GFDL-CM3 & Geophysical Fluid Dynamics Laboratory & \\
3 & GFDL-ESM2G & & \\
4 & GFDL-ESM2M & NASA/GISS Goddard Institute for Space Studies & USA \\
5 & GISS-E2-H & Met Office Hadley Centre & UK \\
6 & GISS-E2-R & Japan & \\
7 & HadGEM2-ES & Atmosphere and Ocean Research Institute, National Institute for Environmental & Studies, and Japan Agency for Marine-Earth Science and Technology \\
8 & MIROC-ESM & &
\end{tabular}

\subsection{Research}

\subsubsection{Reference Crop Evapotranspiration $\left(\mathrm{ET}_{0}\right)$}

In this study, the PM equation recommended by FAO was used to calculate $\mathrm{ET}_{0}$, and the calculation process is as follows [37,38]:

$$
E T_{0}=\frac{0.408 \Delta\left(R_{n}-G\right)+\gamma \frac{900}{T+273} U_{2}\left(e_{s}-e_{a}\right)}{\Delta+\gamma\left(1+0.34 U_{2}\right)}
$$

where $E T_{0}$ denotes the reference crop evapotranspiration ( $\mathrm{mm} /$ day), $R_{n}$ denotes the net radiation of crop surface $\left(\mathrm{MJ} /\left(\mathrm{m}^{2} . \mathrm{d}\right)\right), G$ denotes soil heat flux $\left(\mathrm{MJ} /\left(\mathrm{m}^{2} . \mathrm{d}\right)\right), T$ denotes the daily mean temperature at a height of $2 \mathrm{~m}\left({ }^{\circ} \mathrm{C}\right), U_{2}$ denotes the wind speed at a height of $2 \mathrm{~m}(\mathrm{~m} / \mathrm{s}), e_{s}$ denotes the saturated vapor pressure $\left(\mathrm{kPa} /{ }^{\circ} \mathrm{C}\right)$, and $\gamma$ denotes the hygrometer constant $\left(\mathrm{kPa} /{ }^{\circ} \mathrm{C}\right)$.

\subsubsection{Calculation of Standardized Precipitation Evapotranspiration Index (SPEI)}

SPEI is a drought index that reflects water deficit at different time scales, based on $\mathrm{ET}_{0}$ and precipitation. Therefore, SPEI can describe the aspects of drought caused by changes in meteorological factors such as precipitation and temperature. Table 2 shows the drought degree corresponding to the SPEI index in the different ranges in this article.

Table 2. SPEI Drought/Moist classification grade.

\begin{tabular}{ccc}
\hline Grade & SPEI & Category \\
\hline 1 & $>2.00$ & Extreme moist \\
2 & $1.5 \sim 1.99$ & Severe moist \\
3 & $1 \sim 1.49$ & Slight moist \\
4 & $-0.99 \sim 0.99$ & Normal \\
5 & $-1.00 \sim-1.49$ & Mild drought \\
6 & $-1.20 \sim-1.99$ & Severe drought \\
7 & $<-2.00$ & Extreme drought \\
\hline
\end{tabular}


For a specific month, water deficit, $D$, and rainfall, $P e$, minus reference crop evapotranspiration, $E T_{0}$. The equation is as follows:

$$
D=P e-E T
$$

Monthly cumulative water deficit for a given year, $i$, with a time scale of 12 months is calculated as follows [23]:

$$
\begin{gathered}
X_{i, j}^{k}=\sum_{m=13-k+1}^{12} D_{i-1, m}+\sum_{m=1}^{j} D_{i, m} \quad j<k \\
X_{m=j-k+1}^{k} D_{i, m} \quad j \geq k
\end{gathered}
$$

where $X_{i, j}^{k}$ denotes the cumulative water deficit in month $j$ in year $i, k$ denotes the selected time scale, and $k$ is 12 months in this study.

The probability distribution of the three-parameter log-logistic distribution was used to calculate SPEI, and the distribution function is [23]:

$$
F_{(x)}=\left[1+\left(\frac{\alpha}{x-\gamma}\right)^{\beta}\right]^{-1}
$$

where $x$ is the value in the acceptable range $(\gamma<x<\infty)$; the equations of $\alpha, \beta$, and $\gamma$ is as follows [23]:

$$
\begin{gathered}
\beta=\frac{2 \omega_{1}-\omega_{0}}{6 \omega_{1}-\omega_{0}-6 \omega_{2}} \\
\alpha=\frac{\left(\omega_{0}-2 \omega_{1}\right) \beta}{\Gamma(1+1 / \beta) \Gamma(1-1 / \beta)} \\
\gamma=\omega_{0}-\alpha \Gamma(1+1 / \beta) \Gamma(1-1 / \beta) \\
\omega_{s}=\frac{1}{N} \sum_{i=1}^{N}\left(1-\frac{i-0.35}{N}\right)^{s} X_{i}
\end{gathered}
$$

where $i$ denotes the ascending sequence number of cumulative water deficit $\left(X_{1} \leq X_{2} \ldots \leq X_{n}\right)$, $N$ denotes the number of samples, and $\Gamma(\beta)$ denotes the gamma function of $\beta$. Pe was defined as the part that exceeds the determined $D$, and SPEI was calculated [23]:

$$
\begin{gathered}
P e=1-F(x) \\
W=\sqrt{-2 \ln (P e)}, P e \leq 0.5 \\
S P E I=W-\frac{c_{0}+c_{1} W+c_{2} W^{2}}{1-d_{1} W+d_{2} W^{2}+d_{3} W^{3}} \\
W=\sqrt{-2 \ln (1-P e)}, P e>0.5 \\
S P E I=\frac{c_{0}+c_{1} W+c_{2} W^{2}}{1-d_{1} W+d_{2} W^{2}+d_{3} W^{3}}-W
\end{gathered}
$$

\subsubsection{MK Test}

The Mann-Kendall (MK) trend test is a non-parametric method [21], which has a wider test range, and the required data does not need to follow a specific distribution. It is commonly used to examine the variation trend of a data series with time [39]. This study used this method to perform a test for annual mean temperature, annual mean 
precipitation, annual mean $\mathrm{ET}_{0}$, and SPEI in the Huang-Huai-Hai region. The specific steps are as follows [40]:

$$
\begin{gathered}
S=\sum_{k=1}^{n-1} \sum_{l=k+1}^{n} \operatorname{sgn}\left(X_{l}-X_{k}\right) \\
\operatorname{sgn}\left(X_{l}-X_{k}\right)= \begin{cases}+1 & \text { if }\left(X_{l}-X_{k}\right)>0 \\
0 & \text { if }\left(X_{l}-X_{k}\right)=0 \\
-1 & \text { if }\left(X_{l}-X_{k}\right)<0\end{cases} \\
\operatorname{Var}(S)=\frac{1}{18}\left[n(n-1)(2 n+5)-\sum_{p=1}^{q} t_{p}\left(t_{p}-1\right)\left(2 t_{p}+5\right)\right] \\
Z_{c}= \begin{cases}\frac{S-1}{\sqrt{\operatorname{Var}(S)}} & \text { if } S>0 \\
0 & \text { if } S=0 \\
\frac{S-1}{\sqrt{\operatorname{Var}(S)}} & \text { if } S<0\end{cases}
\end{gathered}
$$

where $X_{k}$ and $X_{l}$ denote the values in the $k$ th and lst year in the time series, respectively, $n$ denotes the length of time series data, $t_{p}$ denotes the binding value corresponding to the $p$ th digit, and $Z_{c}$ denotes the variation trend of time series data.

For a given confidence level, $\alpha$, if $\left|Z_{c}\right|>Z_{(1-\alpha / 2)}$, this indicates rejection of the null hypothesis, suggesting that data series have a significant rising or descending trend; otherwise, the trend is not significant. When the standard statistical variable is $Z_{c}>0$, this indicates that the time series has a rising trend. When it is $Z_{c}<0$, this indicates that the time series has a decreasing trend [21].

\section{Results}

\subsection{Evolution of Meteorological Factors in Huang-Huai-Hai Region}

\subsubsection{Temperature Change}

The spatiotemporal distribution of annual mean temperature in the Huang-Huai-Hai region is shown in Figure 2. The range of annual mean temperature ranges from $6.5^{\circ} \mathrm{C}$ to $20.8^{\circ} \mathrm{C}$. On the whole, the annual mean temperature in this area gradually decreases from the south to the north, and the temperature in the south and east is higher, while that in the northwest is lower. In general, the temperature under the RCP8.5 scenario is higher than that under RCP2.6 and RCP4.5. Under the RCP2.6 scenario, the annual mean temperature is $6.5-17.2{ }^{\circ} \mathrm{C}, 6.8-17.4{ }^{\circ} \mathrm{C}$, and $6.5-17.3{ }^{\circ} \mathrm{C}$ in the 2030s, 2050s, and 2080s, respectively. Under RCP4.5, the mean temperature is $6.5-17.1^{\circ} \mathrm{C}, 7.3-17.9^{\circ} \mathrm{C}$, and $8.1-18.5^{\circ} \mathrm{C}$ in the $2030 \mathrm{~s}, 2050 \mathrm{~s}$, and 2080s, respectively. Under the RCP8.5 scenario, the mean temperature is $6.8-17.4^{\circ} \mathrm{C}, 8.0-18.5^{\circ} \mathrm{C}$, and $10.5-20.8^{\circ} \mathrm{C}$ in the $2030 \mathrm{~s}, 2050 \mathrm{~s}$, and $2080 \mathrm{~s}$, respectively. The temperature difference between the three scenarios in the 2030s is smaller, and the spatial distribution pattern of temperature is similar. In the 2050s, the temperature of the three scenarios will increase by approximately $0.5^{\circ} \mathrm{C}$. In the 2080s, the temperature shows an obvious increase in the three scenarios. The annual mean temperature of RCP4.5 is $1.2-1.6^{\circ} \mathrm{C}$ higher than that of RCP2.6, and that of RCP8.5 is $2.3{ }^{\circ} \mathrm{C}$ higher than that of $\mathrm{RCP} 4.5$. With the increase of time, the area with the higher temperature in the south of the region sees a gradual rise in temperature, while the area with lower temperature in the northwest of the Huang-Huai-Hai region sees a gradual decline in temperature. This trend is more evident under the RCP8.5 scenario. 

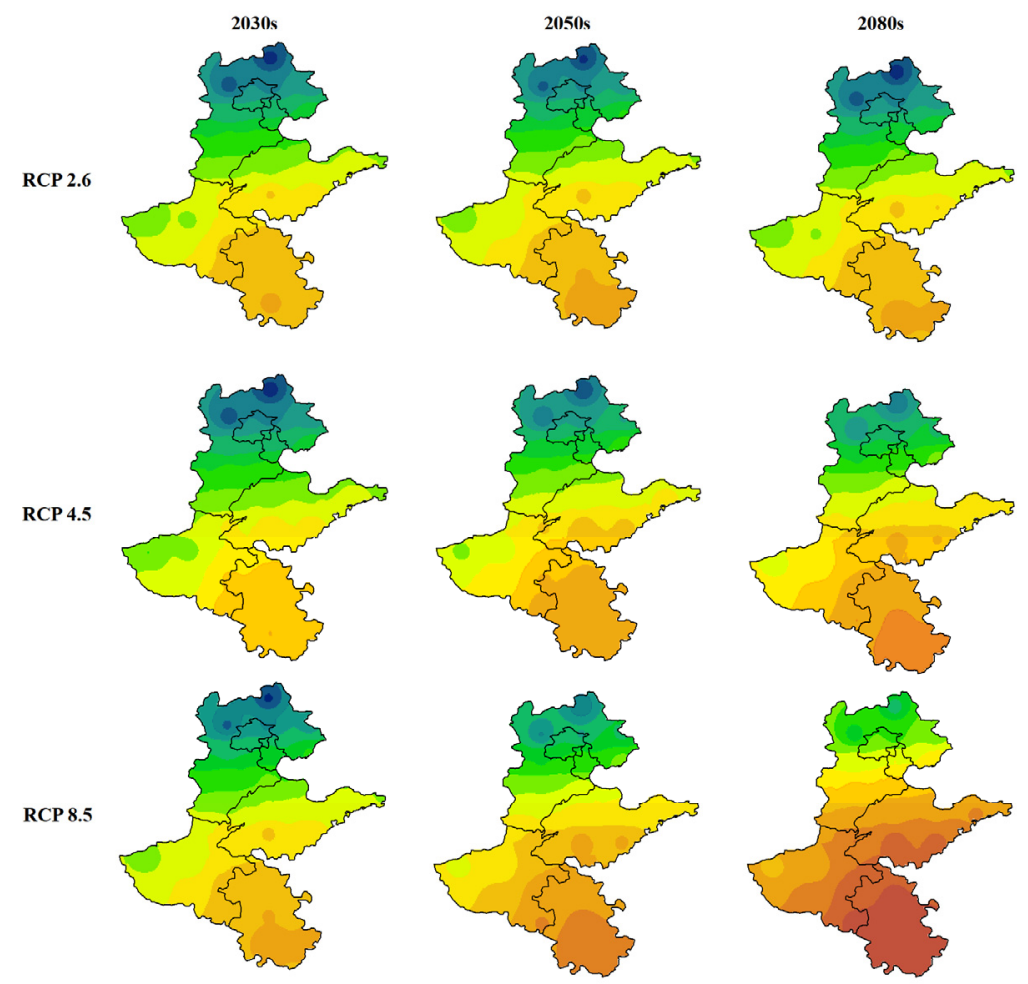

$\mathbf{T}_{\text {mean }}\left({ }^{\circ} \mathrm{C}\right)$

Figure 2. Spatiotemporal distribution of temperature under future climate scenarios.

Based on the MK trend test, the variation of mean temperature in future climate scenarios can be obtained, as shown in Figure 3. Among them, the variation trend of mean temperature in emission scenarios with different concentrations greatly differ. In the RCP2.6 scenario, the $Z_{c}$ value range of annual mean temperature is between -1.5 and 2.5, and the annual mean temperature in the western Huang-Huai-Hai region shows a downward trend. In the RCP4.5 scenario, the $Z_{c}$ value range of annual mean temperature is 7.8-8.8, and the annual mean temperature in the whole region shows a substantial increasing trend. In the RCP8.5 scenario, the $Z_{c}$ value range of annual mean temperature is 9.9-10.4. At this time, the annual mean temperature in Huang-Huai-Hai region shows an extremely significant increasing trend, especially in the northeast region, where the $Z_{c}$ value range of annual mean temperature is between 10.3 and 10.4.
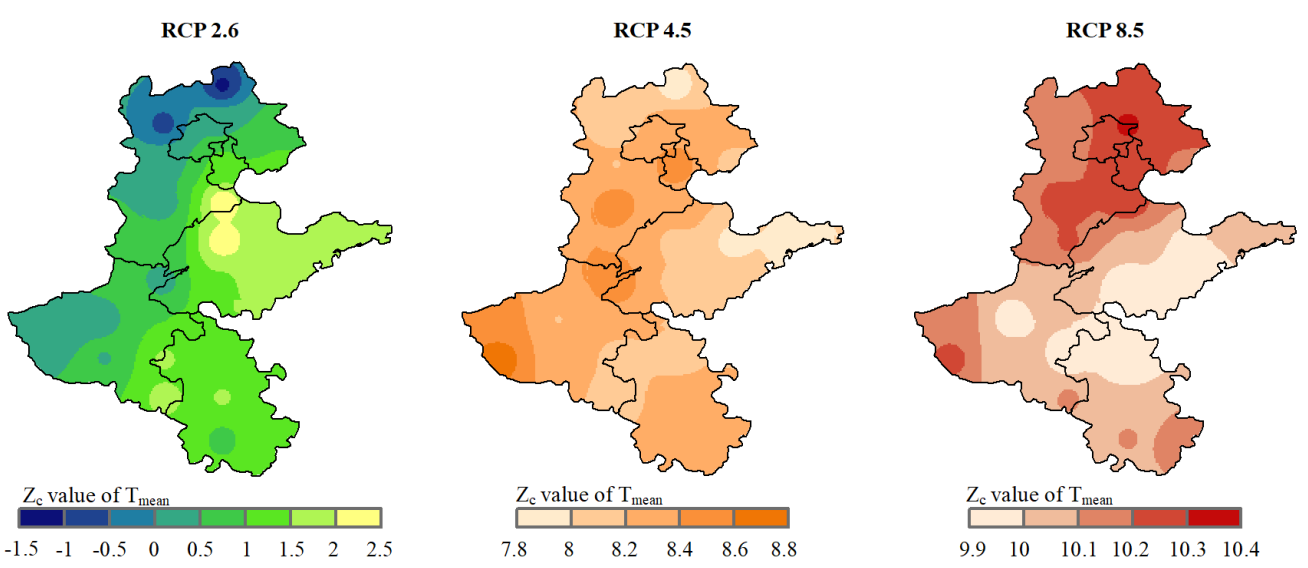

Figure 3. The MK trend test of temperature under future climate scenarios. 


\subsubsection{Precipitation Change}

The spatiotemporal distribution of precipitation in the future climate scenarios are shown in Figure 4. In terms of spatial distribution, precipitation successively increases from the north to the south, with less precipitation in the northwest of the HuangHuai-Hai region and more precipitation in the southeast region. In the RCP2.6 scenario, the precipitation ranges from $432 \mathrm{~mm}$ to $1114 \mathrm{~mm}$ in the 2030s, from $566 \mathrm{~mm}$ to $1482 \mathrm{~mm}$ in the 2050s, and from $601 \mathrm{~mm}$ to $1579 \mathrm{~mm}$ in the 2080s. In the RCP4.5 scenario, it ranges from $574 \mathrm{~mm}$ to $1530 \mathrm{~mm}$ in the 2030s, $432 \mathrm{~mm}$ to $1622 \mathrm{~mm}$ in the 2050s, and $613 \mathrm{~mm}$ to $1561 \mathrm{~mm}$ in the 2080s. Under the RCP8.5 scenario, the values are from $547 \mathrm{~mm}$ to $1507 \mathrm{~mm}$ in the 2030s, $590 \mathrm{~mm}$ to $1489 \mathrm{~mm}$ in the 2050s, and 667-1622 mm in the 2080s. Precipitation in the RCP2.6 scenario has an evident increasing trend with time, but this is not particularly obvious under the RCP4.5 and RCP8.5 scenarios. However, in any scenario, the higher precipitation area shows an expanding trend with time. Especially under the RCP2.6 and RCP8.5 scenarios, the higher precipitation area in the northwest and southeast of the Huang-Huai-Hai region gradually expands from 2030 to 2080, such as Hebei and Anhui.
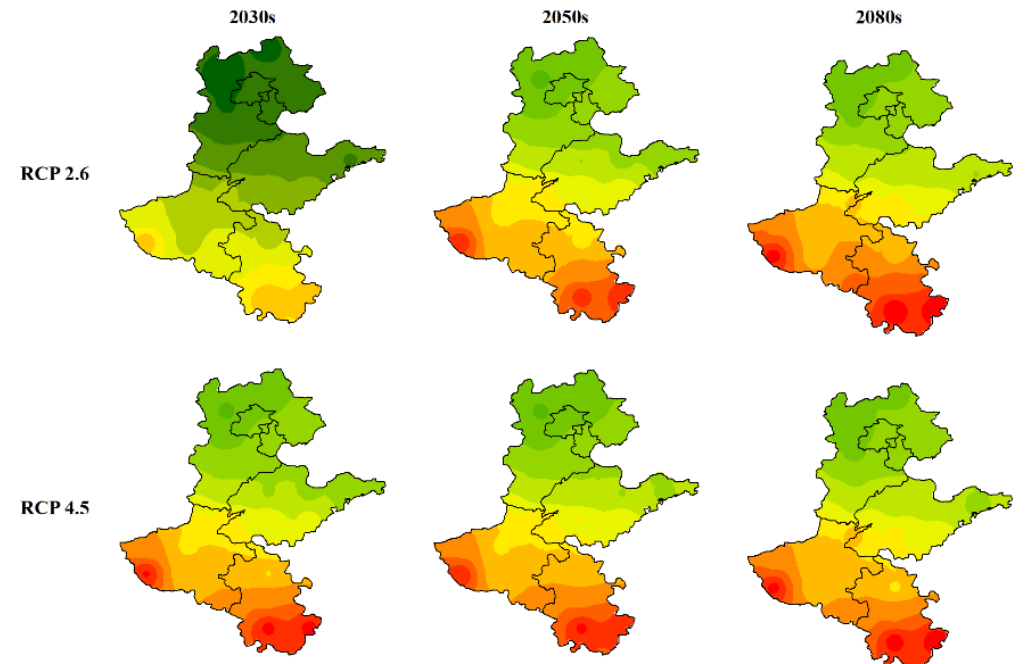

RCP 8.5
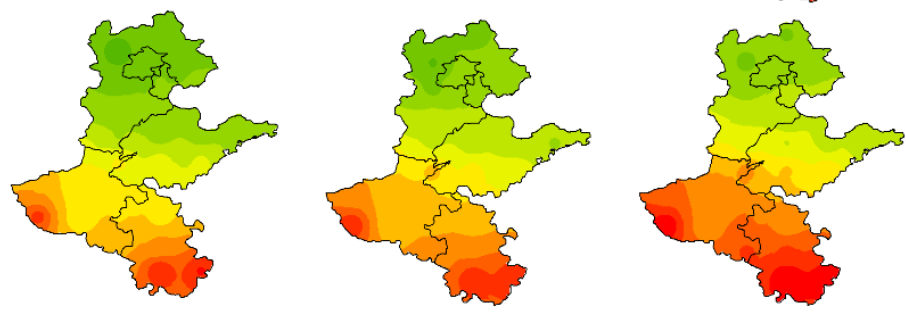

$\mathrm{Pe}_{\mathrm{e}}(\mathrm{mm})$

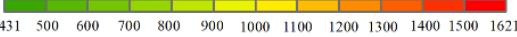

Figure 4. Spatiotemporal distribution of precipitation under future climate scenarios.

In the future climate scenarios, the MK trend change of annual mean precipitation in the Huang-Huai-Hai region is shown in Figure 5 , and the $Z_{c}$ value range of annual mean precipitation is between -0.73 and 5.3. Except for the decreasing trend of precipitation in some regions under the RCP2.6 scenario, almost all ranges in the Huang-Huai-Hai region show an increasing trend under the other two scenarios. In the RCP2.6 scenario, the $Z_{c}$ value range of annual mean precipitation is $-0.73-1.6$, and the southeast of the region shows a downward trend, especially at the junction of Henan and Anhui. Under the RCP4.5 scenario, the $Z_{c}$ value range of annual mean precipitation is $-0.3-3.9$. Except for a small part of Hebei, the precipitation in the Huang-Huai-Hai region presents a rising trend, and the increase amplitude in the western territory is greater than that in the eastern. In the RCP8.5 scenario, the $Z_{c}$ value range of annual mean precipitation is 1.6-5.3, and the precipitation in the whole Huang-Huai-Hai region presents an increasing trend. 
The distribution trend of precipitation is similar to that in RCP4.5, and the increase amplitude in the western region is greater than that in the eastern region. From the perspective of spatial alternation, the variation trend of precipitation in the region shows the obvious east-west difference. In possible events of all three emissions, the precipitation in the west has a larger increasing trend.
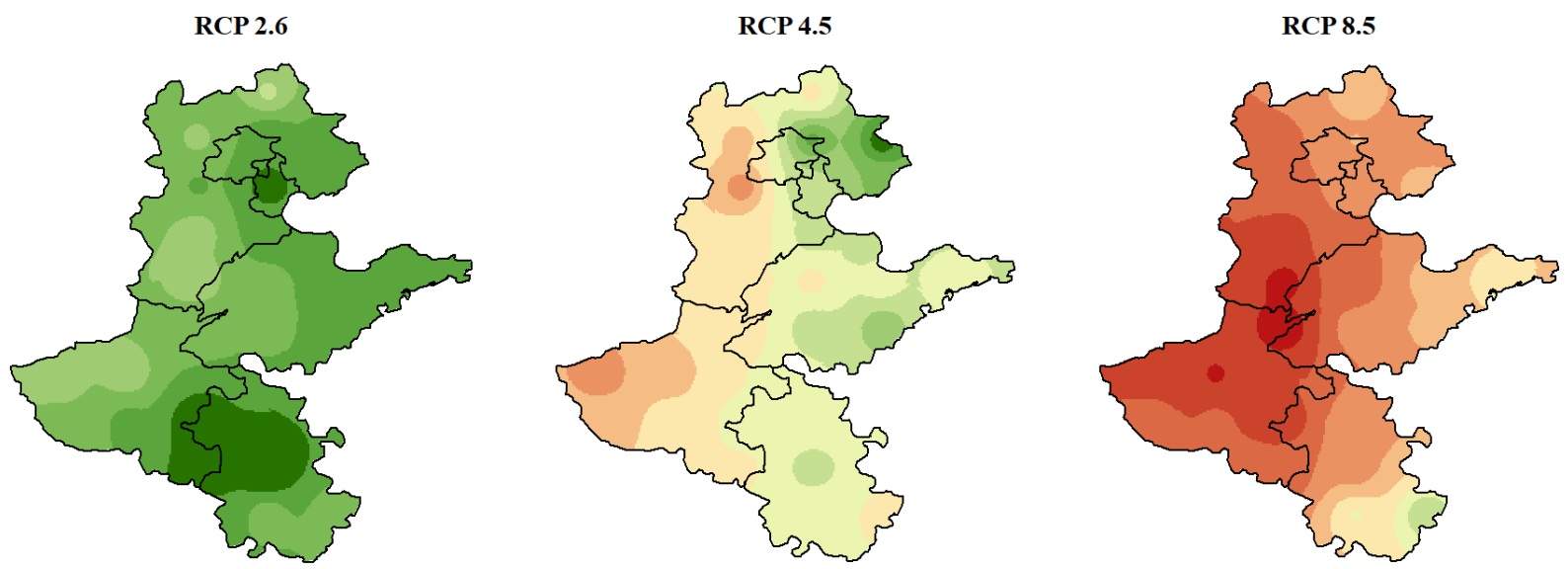

$\mathrm{Z}_{\mathrm{c}}$ Value of $\mathrm{Pe}$

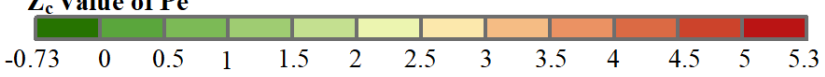

Figure 5. MK trend test of precipitation under future climate scenarios.

\subsection{Evolution of $E T_{0}$ in the Huang-Huai-Hai Region under Future Climate Change Scenarios}

In this study, the PM equation was used to calculate the reference crop evapotranspiration, $\mathrm{ET}_{0}$, in the Huang-Huai-Hai region under future climate scenarios. The spatiotemporal distribution of the annual mean $\mathrm{ET}_{0}$ in the region is shown in Figure 6. The spatial distribution of annual mean $\mathrm{ET}_{0}$ in the Huang-Huai-Hai region is similar under the three scenarios. The spatial distribution is higher in the east, especially in Shandong. It is relatively lower in the northwest and the southwest, especially in northern Hebei and western Henan. In the RCP2.6 scenario, the annual mean ET 0 in the HuangHuai-Hai region varies from $1611 \mathrm{~mm}$ to $2017 \mathrm{~mm}$ in the 2030s, from $1670 \mathrm{~mm}$ to $2058 \mathrm{~mm}$ in the 2050s, and from $1618 \mathrm{~mm}$ to $2079 \mathrm{~mm}$ in the 2080s. $\mathrm{ET}_{0}$ continues to increase over time, and the increase from the 2030s to the 2050s is larger than that from the 2050s to the 2080s. However, the spatial distribution of $\mathrm{ET}_{0}$ in this scenario changes insignificantly between years. In the RCP4.5 scenario, the annual mean $\mathrm{ET}_{0}$ in the Huang-Huai-Hai region ranges from $1622 \mathrm{~mm}$ to $1989 \mathrm{~mm}$ in the 2030s, from $1674 \mathrm{~mm}$ to $2094 \mathrm{~mm}$ in the 2050s, and from $1733 \mathrm{~mm}$ to $2125 \mathrm{~mm}$ in the 2080s. From the 2050s to the 2080s, the increase amplitude of $\mathrm{ET}_{0}$ is slower than that of the previous decade, but is larger than that in the RCP2.6 scenario. In the RCP8.5 scenario, the annual mean $\mathrm{ET}_{0}$ in the Huang-Huai-Hai region varies from $1627 \mathrm{~mm}$ to $2022 \mathrm{~mm}$ in the 2030s, from $1678 \mathrm{~mm}$ to $2104 \mathrm{~mm}$ in the 2050s, and from $1820 \mathrm{~mm}$ to $2217 \mathrm{~mm}$ in the 2080s. The increase amplitude of $\mathrm{ET}_{0}$ during the period 2050s-2080s is larger than that in the previous decade. In this context, the spatial distribution of $\mathrm{ET}_{0}$ varies significantly between different decades. With the increase of decade, the area with the larger $\mathrm{ET}_{0}$ is constantly expanding; especially in the 2080s, $\mathrm{ET}_{0}$ in almost the entire Huang-Huai-Hai region is above $2000 \mathrm{~mm}$. By comparing the three scenarios, it can be seen that the area with the smaller $\mathrm{ET}_{0}$ in the three scenarios is continuously shrinking, while the area with larger $\mathrm{ET}_{0}$ is continuously expanding. This change trend is more evident in the RCP8.5 scenario. 


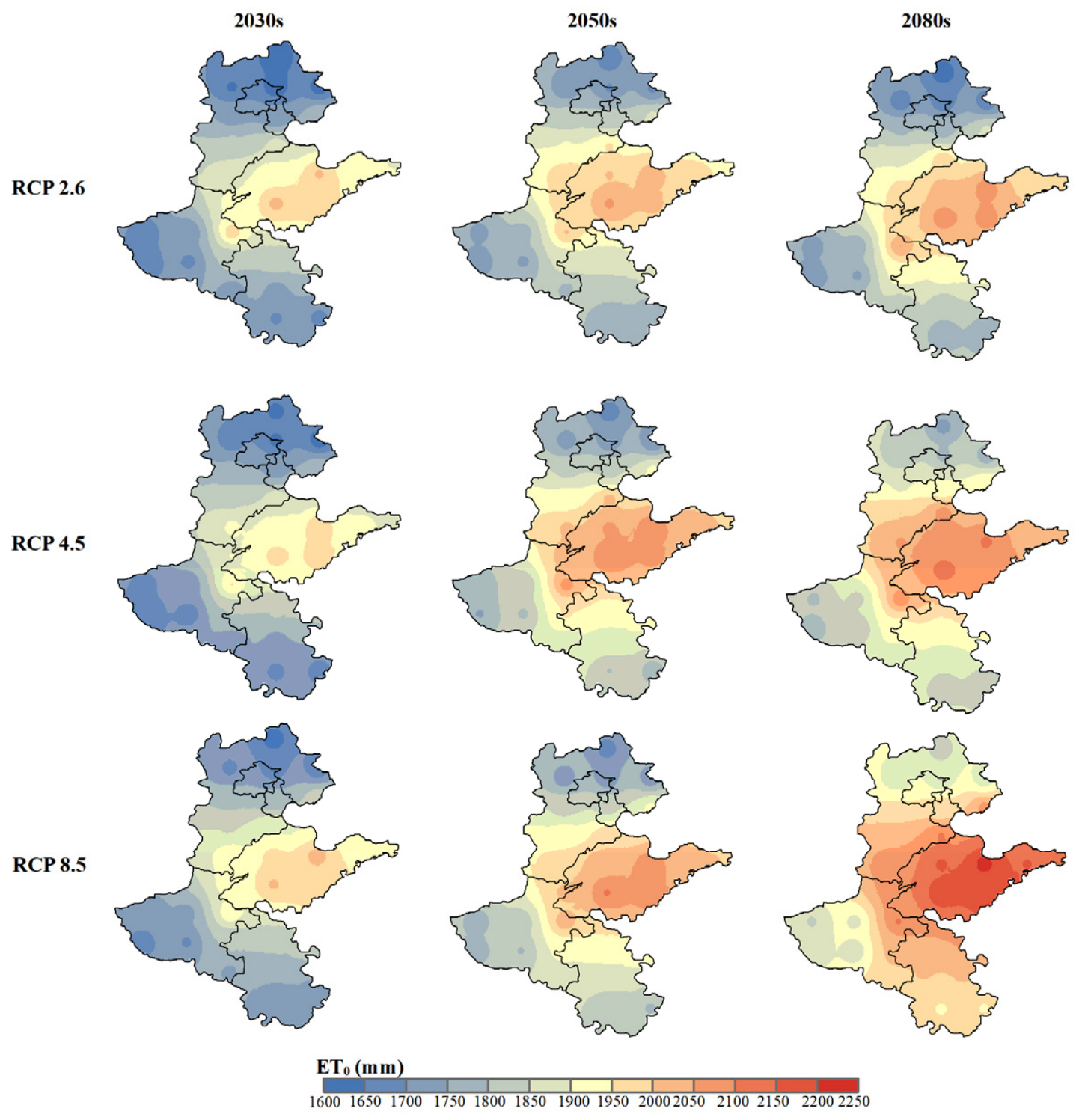

Figure 6. Spatiotemporal distribution of $\mathrm{ET}_{0}$ under future climate scenarios.

\subsection{Evolution of SPEI in the Huang-Huai-Hai Region under Future Climate Change Scenarios}

Figure 7 shows the spatial variation of SPEI under different scenarios in the next three decenniums (2030s, 2050s, and 2080s) in the Huang-Huai-Hai region. As can be seen from the illustration of the RCP2.6 scenario, the annual mean SPEI in the Huang-Huai-Hai region varies from -2.3 to 1.8 in the 2030s, from -2.5 to 2.4 in the $2050 \mathrm{~s}$, and from -1.8 to 2.3 in the 2080s. In the RCP4.5 scenario, the annual mean SPEI in the Huang-Huai-Hai region varies from -1.8 to 2.1 in the 2030 s, from -2.8 to 2.5 in the $2050 \mathrm{~s}$, and from -2.7 to 2.2 in the 2080s. In the RCP8.5 scenario, the annual mean SPEI in the Huang-Huai-Hai region varies from $-3.0-2.7$ in the $2030 \mathrm{~s}$, from -2.7 to 2.7 in the $2050 \mathrm{~s}$, and from -2.0 to 2.1 in the 2080s. In the RCP8.5 scenario, the drought degree reduces with the increase of decade. The drought degree in the other two scenarios expands over time but is alleviated to some extent in the 2080s. From the perspective of spatial distribution, the area of severe drought in the north is larger, and the area of severe drought in the same period increases with the expansion of the concentration in the emission scenario, and this variation trend is more apparent in the RCP2.6 scenario. 

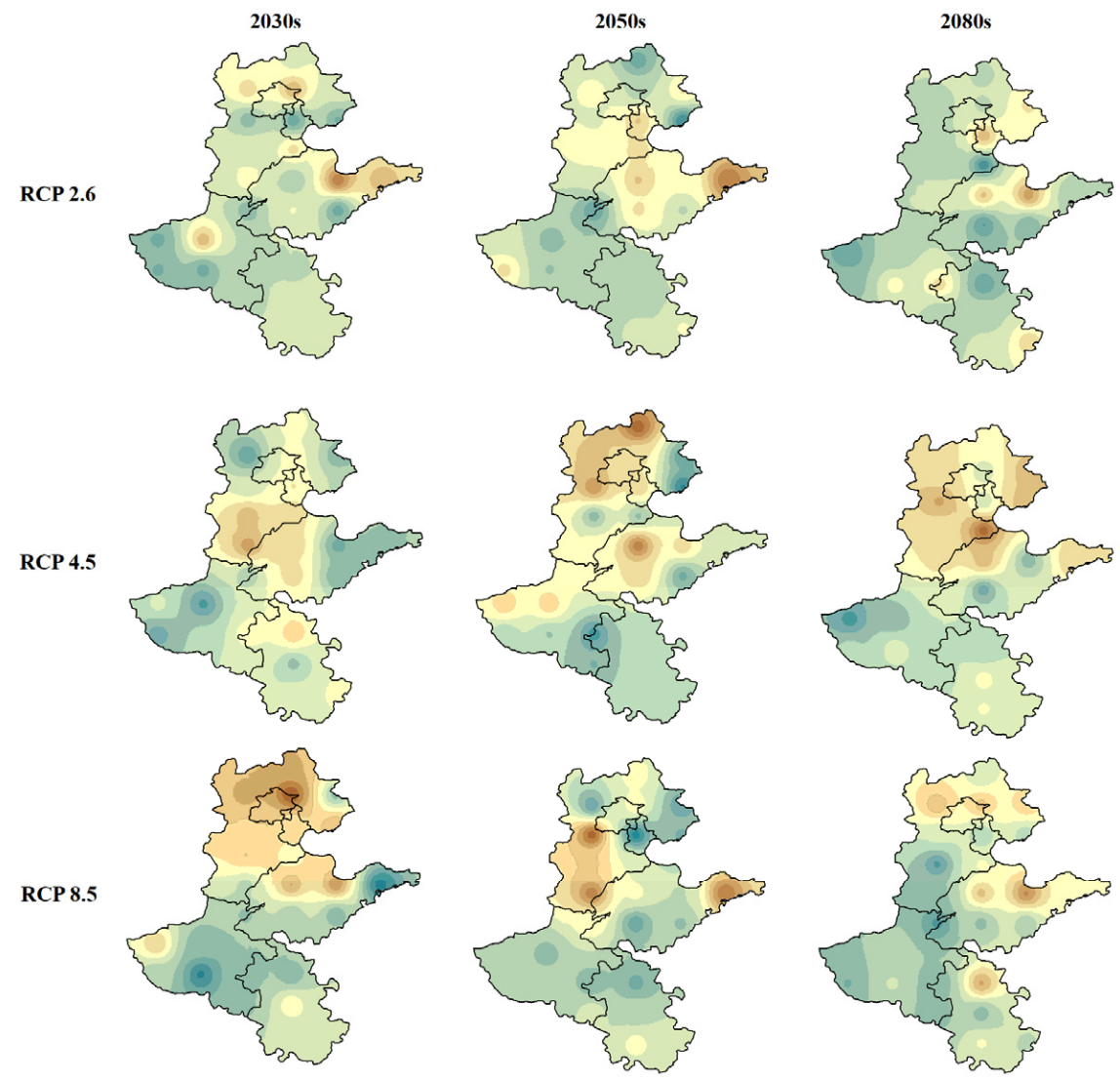

SPEI

Figure 7. Spatiotemporal distribution of SPEI under future climate scenarios (2030s, 2050s, and 2080s).

As can be seen from Figure 8, the variation range of SPEI is smaller under RCP2.6, the value of $Z_{c}$ ranging from -1.4 to 1.4. The variation range of SPEI is large under RCP4.5 and RCP8.5, the value of $Z_{c}$ ranging from -2 to 2.1 and -2.8 to 2 , respectively. With the growth of emission scenario concentration, the area of increasing SPEI gradually expands. Under the RCP2.6 scenario, most regions of Shandong and Anhui show a downward trend, while Henan and Hebei show a slight upward trend. In the RCP4.5 scenario, SPEI in southern Anhui and the central Hebei decreases slightly, while that in the central HuangHuai-Hai region increases. Under the RCP8.5 scenario, the northwest China and southern Anhui indicate an obvious trend of increasement, while Shandong, southern Henan, and northern Anhui show an obvious trend of decline.
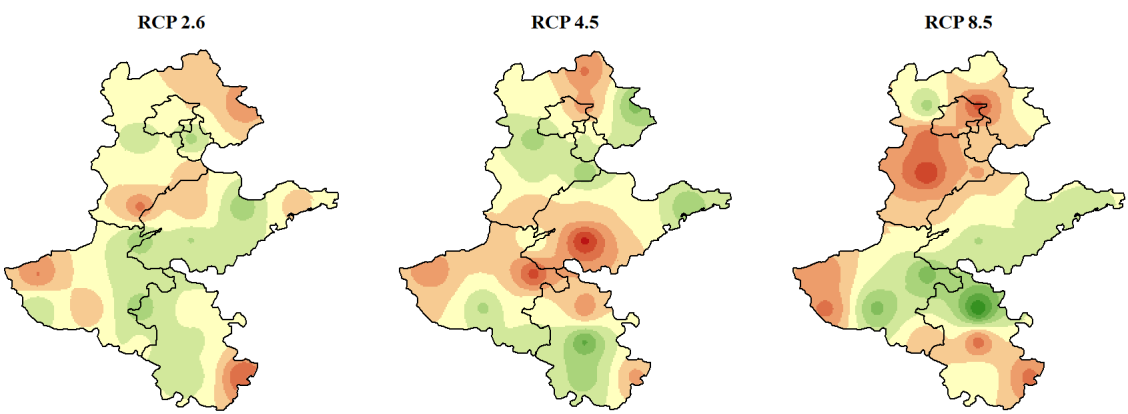

$\mathrm{Z}_{\mathrm{c}}$ value of SPEI

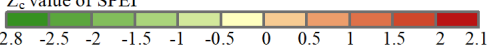

Figure 8. MK trend test of SPEI under future climate scenarios. 


\section{Discussion}

\subsection{Impact of the Future Climate Change on $E T_{0}$}

Compared with the baseline level (1976-2005), the change of $\mathrm{ET}_{0}$ level of representative stations in each province under future climate scenarios is shown in Figure 9. The results indicate that, compared with the baseline scenario (1976-2005), the $\mathrm{ET}_{0}$ level in the 2030s, 2050s, and 2080s shows an upward trend. In the 2080s, the station with the largest growth of $\mathrm{ET}_{0}$ is in Henan in the RCP2.6 scenario, with a growth rate of $10.7 \%$. In the RCP4.5 scenario, Hebei has the largest growth rate of $13.5 \%$, while in the RCP8.5 scenario, Anhui has the largest growth rate of $21 \%$. The results of the MK trend test for the annual mean $\mathrm{ET}_{0}$ under future climate scenarios are presented in Figure 9. It can be seen that the $Z_{c}$ values of $\mathrm{ET}_{0}$ are all greater than zero, between 0.6 and 8.2, and the increase amplitude rises with the increase of concentration in emission scenarios. The $Z_{\mathcal{c}}$ value of the $\mathrm{ET}_{0}$ range is $0.6-4$ in the RCP2.6 scenario. $\mathrm{ET}_{0}$ in the eastern Huang-Huai-Hai Region increases importantly, especially in Anhui, Henan, and eastern Shandong. In the RCP4.5 scenario, the range of $Z_{c}$ value of $\mathrm{ET}_{0}$ is 3-6, and $\mathrm{ET}_{0}$ increases greatly in the northwest of the Huang-Huai-Hai region, especially in Hebei. In the RCP8.5 scenario, the range of $Z_{c}$ value of $\mathrm{ET}_{0}$ is $5-8.2$, and that in the southeast of Huang-Huai-Hai region notably increases, especially in Anhui.
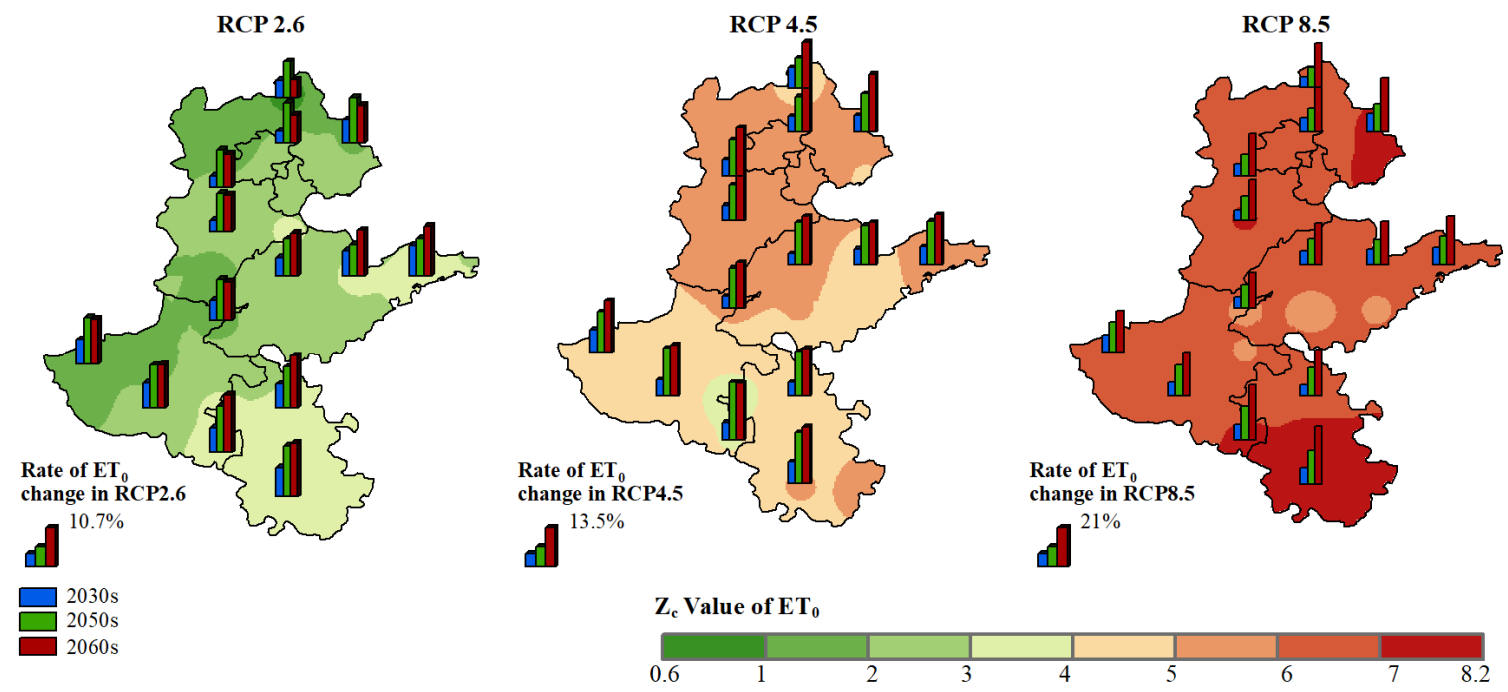

Figure 9. $Z_{c}$ values of $\mathrm{ET}_{0}$ in the $\mathrm{MK}$ trend test and the rate of decadal $\mathrm{ET}_{0}$ variation in major stations in different $\mathrm{RCP}$ scenarios.

Apparently, in different emission scenarios, the annual mean $\mathrm{ET}_{0}$ in most areas of the Huang-Huai-Hai region increases with the increase of decade. At the same time, the increased amplitude of annual mean $\mathrm{ET}_{0}$ in this area becomes higher with the increase of emission concentration in the scenarios. Li et al. [41] also predicted that $\mathrm{ET}_{0}$ in China would manifest an obvious growth gradient from the northeast to the southwest from 2011 to 2099. Liu et al. [42] studied the changes of $\mathrm{ET}_{0}$ in areas with different elevations over the Tibetan Plateau during the period 1961-2017 and found that the annual mean $\mathrm{ET}_{0}$ showed an upward trend within the study period, and mean temperature and wind speed played an important role in $\mathrm{ET}_{0}$ change. Wang et al. [43] found that $\mathrm{ET}_{0}$ in northwest China increased significantly with the evident increase of temperature. In this study, the variation trend of annual mean temperature in the Huang-Huai-Hai region under future meteorological conditions was compared. It was found that, with the increase of greenhouse gas concentration in the emission scenarios, both the mean temperature and the annual mean $\mathrm{ET}_{0}$ showed an increasing trend, but the $Z_{c}$ value spatial variation trend of temperature was not completely consistent with that of $\mathrm{ET}_{0}$. For example, under the RCP8.5 scenario, the mean temperature of Hebei in the north of the Huang-HuaiHai region increases the most, while the annual mean $\mathrm{ET}_{0}$ of Anhui in the south of the 
region essentially increases. This also indicates that temperature knowledge is one of the main factors affecting the change of $\mathrm{ET}_{0}$. According to the $\mathrm{PM}$ equation, we can also see that the main meteorological factors affecting $\mathrm{ET}_{0}$ include air humidity, temperature, wind speed, and solar radiation. Zhang et al. [44] found that, in arid and semi-arid regions of China, $\mathrm{ET}_{0}$ was more sensitive to air humidity, followed by solar radiation, temperature, and wind speed. Gao et al. [45] found that the change rates of air humidity, solar radiation, temperature, and wind speed were very small during the study period based on meteorological data from 2001 to 2050, thus there was no significant change of $\mathrm{ET}_{0}$ in the RCP2.6 and R8.5 scenarios. Roderick and Farquhar [46] believed that the evaporation change rate of the northern hemisphere decreased steadily at $2-4 \mathrm{~mm} / \mathrm{a}^{2}$ in the past $50 \mathrm{a}$, resulting in the phenomenon of "evaporation paradox".

\subsection{The Drought Occurrence in Future Climate Scenarios}

As can be seen from Figure 8, there are important differences in the changes of SPEI in different emission scenarios, suggesting that the aspects of drought in future climate scenarios are related to the concentration in the emission path. In the case of the high emission scenario (RCP8.5), SPEI in the Huang-Huai-Hai region shows a decreasing trend. SPEI in the same emission scenario also has significant spatial differences with time. Most droughts occur in the northern Huang-Huai-Hai region. The area of drought that occurred in THE RCP2.6 and RCP4.5 scenarios increases slightly with time, and that in the 2080s decreases significantly. In the RCP8.5 scenario, the area of drought has been decreasing over time. This might be due to the gradual increase of precipitation over time, which alleviates drought conditions in some areas. As the emission concentration increases, the temperature keeps rising, leading to the increase of $\mathrm{ET}_{0}$. As a result, the precipitation and $\mathrm{ET}_{0}$ difference lessens more and more. Therefore, in the RCP8.5 scenario, the drought state in the Huang-Huai-Hai region is the most severe in the 2030s, while there is more of the moist situation in the region in the 2080s in the RCP2.6 scenario.

Zhao et al. [47] used the SPEI index to analyze the drought in China from 2020 to 2099 , and the conclusion was that there were large differences in the frequency of drought and moist conditions at various time scales. In this study, the percentages of stations with severe drought $\left(Z_{c}<-1.5\right)$ and severe moist $\left(Z_{c}>1.5\right)$ in the lower Huang-Huai-Hai region in the 2030s, 2050s, and 2080s, under different emission scenarios, were estimated. It can be seen that, under the same emission scenario, the frequency of drought and moist conditions in this region also varies greatly at different time scales (Figure 10). In the RCP2.6 and RCP8.5 scenarios, there are more stations with severe drought in the 2030s. In the RCP4.5 scenario, there are more stations with severe drought in the 2050s. In the RCP8.5 scenario, there are more stations experiencing severe drought in the 2030s (Figure 10). According to the MK trend test results (Figure 8), SPEI decreases in a larger area in the RCP8.5 scenario, indicating that there are more drought areas, which is similar to the findings of Wang et al. [48]. Li et al. [49] also predicted that the frequency, duration, severity and intensity of drought in the Huang-Huai-Hai plain would increase under the RCP8.5 scenario. Gao et al. [45] found that 12-month SPEI in Loess Plateau manifested an increasing trend under the RCP8.5 scenario, and the frequency of drought duration decreased significantly in the first half of the 21st century, which was generally consistent with the research results. The area of drought is relatively large in the 2030s, and decreases after the 2050s (Figures 7 and 10). 


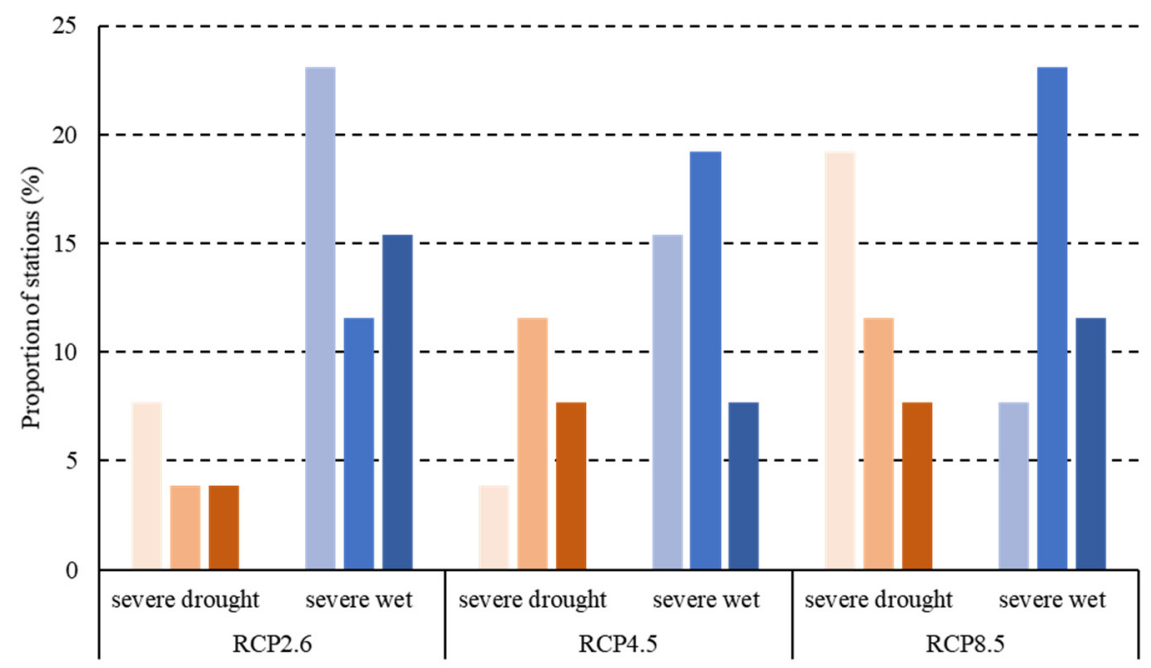

Figure 10. The variation trend of drought and moist under RCP scenarios in the Huang-Huai-Hai region (red represents severe drought and blue stands for severe moist; colors from light to dark represent 2030s, 2050s, and 2080s).

\section{Conclusions}

In future climate scenarios, the temperature and precipitation in the Huang-Huai-Hai region will apparently change. In most of this region, temperature will increase over time, and this trend is more significant in the RCP8.5 scenario. With the increase of emission concentration, areas with higher temperature gradually expand from the south to the north. In the RCP2.6 scenario, the area with the higher temperature is in Anhui. In the RCP4.5 scenario, areas with higher temperature are distributed in Anhui, Shandong, and eastern Henan. In the RCP8.5 scenario, areas with higher temperature include Anhui, Shandong, Henan, and southern Hebei. Most of the Huang-Huai-Hai region has higher temperature, especially in the 2080s. Precipitation also increases with the expansion of greenhouse gas concentration in the emission scenarios. Generally speaking, the growth trend in the west is greater than that in the east. Areas with higher precipitation are mostly distributed in the southern Huang-Huai-Hai region. From the perspective of spatial variation, the areas with higher $\mathrm{ET}_{0}$ in the three emission scenarios gradually increase from the east to the west with time. MK trend test results indicated that, with the increase of greenhouse gas concentration in the emission scenarios, the growth trend of $\mathrm{ET}_{0}$ would be more evident, and the growth trend in RCP8.5 would be much larger than the other two scenarios.

Under future climate conditions, due to the influence of temperature, precipitation, and other meteorological factors, drought in the Huang-Huai-Hai region presents various spatiotemporal distribution characteristics in different scenarios. The severity and area of drought in the RCP8.5 are the largest in the 2030s. This might be due to the continuous increase of precipitation and SPEI with time, and the drought is alleviated to some extent with the increase of decades. According to the MK trend test, SPEI has a great fluctuation with the increase of greenhouse gas concentration in emission scenarios. In the RCP8.5 scenario, the decrease amplitude and extent of SPEI are greater than those in the RCP2.6 and RCP4.5, indicating that drought is more severe in the high emission scenario. This might be caused by the decrease of water resources due to the increase of greenhouse gas concentration, temperature, and $\mathrm{ET}_{0}$ in different emission scenarios.

According to the results of this study, in future climate scenarios, the degree of drought in the Huang-Huai-Hai region will be alleviated to some extent due to the increase of rainfall. However, if greenhouse gas emissionsare not controlled, with the increase of greenhouse gas, the continuously increasing temperature will lead to water shortage and aggravate drought. The government should determine measures to reduce greenhouse gas emissions, develop water-saving agriculture, carefully allocate water resources to alleviate 
drought situation in the Huang-Huai-Hai region in future climate conditions, and ensure food safety and social and economic development in this region.

Author Contributions: Conceptualization, D.Z.; Data curation, J.X. and C.Y.; Formal analysis, S.W.; Investigation, Y.L.; Methodology, B.-L.L.; Writing—review and editing, G.J. and X.G. All authors have read and agreed to the published version of the manuscript.

Funding: This research was funded by Key Research and Development Project of Henan Province (Project No.: 182102310838), the National Natural Science Foundation of China (Project No.: 51879130 and 42077449), the Discipline Innovation and Talent Introduction Base Project of Colleges and Universities in Henan Province of China (Project No.: CXJD2019001), and the Doctoral Research of Nanyang Normal University (Project No.: ZX2014083).

Institutional Review Board Statement: Not applicable.

Informed Consent Statement: Not applicable.

Data Availability Statement: The data presented in this study are available on request from the corresponding author.

Acknowledgments: This research was financially supported by the Key Research and Development Project of Henan Province (Project No.: 182102310838), the National Natural Science Foundation of China (Project No.: 51879130 and 42077449), the Discipline Innovation and Talent Introduction Base Project of Colleges and Universities in Henan Province of China (Project No.: CXJD2019001), and the Doctoral Research of Nanyang Normal University (Project No.: ZX2014083).

Conflicts of Interest: The authors declare no conflict of interest.

\section{References}

1. Murray, V.; Ebi, K.L. IPCC Special Report on Managing the Risks of Extreme Events and Disasters to Advance Climate Change Adaptation (SREX). J. Epidemiol. Community Health 2012, 66, 759-760. [CrossRef]

2. Liu, L.; Hong, Y.; Looper, J.; Riley, R.; Yong, B.; Zhang, Z.; Hocker, J.; Shafer, M. Climatological Drought Analyses and Projection Using SPI and PDSI: Case Study of the Arkansas Red River Basin. J. Hydrol. Eng. 2013, 18, 809-816. [CrossRef]

3. Field, C.B.; Barros, V.; Stocker, T.F.; Dahe, Q. Managing the Risks of Extreme Events and Disasters to Advance Climate Change Adaptation: Special Report of the Intergovernmental Panel on Climate Change; Cambridge University Press: Cambridge, UK, 2012.

4. Wilhite, D.A. Drought as a natural hazard: Concepts and definitions. In A Global Assessment; Routledge: London, UK, 2000; pp. 3-18.

5. Lu, Y.; Cai, H.; Jiang, T.; Sun, S.; Wang, Y.; Zhao, J.; Yu, X.; Sun, J. Assessment of global drought propensity and its impacts on agricultural water use in future climate scenarios. Agric. For. Meteorol. 2019, 278, 107623. [CrossRef]

6. Wang, G.Q.; Zhang, J.Y.; Jin, J.L.; Pagano, T.C.; Calow, R.; Bao, Z.X.; Liu, C.S.; Liu, Y.L.; Yan, X.L. Assessing water resources in China using PRECIS projections and a VIC model. Hydrol. Earth Syst. Sci. 2012, 16, 231-240. [CrossRef]

7. Wang, L.J. Spatiol-Temporal Characteristics of Drought, Heat and Its Effect on Yield for Summer Maize in Huang-Huai-Hai Plain, China. Ph.D. Thesis, China Agricultural University, Beijing, China, 2018. (In Chinese).

8. Yang, J.; Gong, D.; Wang, W.; Hu, M.; Mao, R. Extreme drought event of 2009/2010 over southwestern China. Meteorol. Atmos. Phys. 2012, 115, 173-184. [CrossRef]

9. Zhang, X.X. Comprehensive Spatio-Temporal Evolution of Summer Maize Drought in Huang-Huai-Hai Plain, China. Master's Thesis, Shenyang Agricultural University, Shenyang, China, 2020. (In Chinese).

10. Burke, E.J.; Brown, S.J.; Christidis, N. Modeling the recent evolution of global drought and projections for the twenty-first century with the Hadley Centre climate model. J. Hydrometeorol. 2006, 7, 1113-1125. [CrossRef]

11. Arnell, N.W. Climate change and global water resources: SRES emissions and socio-economic scenarios. Glob. Environ. Chang. 2004, 14, 31-52. [CrossRef]

12. Bannayan, M.; Eyshi, R.E. Future production of rainfed wheat in Iran (Khorasan province): Climate change scenario analysis. Mitig. Adapt. Strateg. Glob. Chang. 2014, 19, 211-227. [CrossRef]

13. Leng, G.; Tang, Q.; Rayburg, S. Climate change impacts on meteorological, agricultural and hydrological droughts in China. Glob. Planet. Chang. 2015, 126, 23-34. [CrossRef]

14. Huang, S.; Wortmann, M.; Duethmann, D.; Menz, C.; Shi, F.; Zhao, C.; Su, B.; Krysanova, V. Adaptation strategies of agriculture and water management to climate change in the Upper Tarim River basin, NW China. Agric. Water Manag. 2018, 203, $207-224$. [CrossRef]

15. Wu, Y.-F.; Bake, B.; Li, W.; Wei, X.-Q.; Wozatihan, J.; Rasulov, H. Spatio-temporal variation of drought condition during 1961 to 2012 based on composite index of meteorological drought in Altay region, China. Ying Yong Sheng Tai Xue Bao J. Appl. Ecol. 2015, $26,512-520$. 
16. Tao, R.; Zhang, K. PDSI-based analysis of characteristics and spatiotemporal changes of meteorological drought in China from 1982 to 2015. Water Resour. Prot. 2020, 426, 50-56.

17. Qu, X.; Yang, Q.; Wang, H.; Cao, Q.; Lin, C. Characteristics of Meteorological Drought Intensity in Inner Mongolia Based on MCI. Meteorol. Environ. Sci. 2019, 42, 47.

18. Jie, W.; Zhuguo, M. Comparison of Palmer Drought Severity Index, Percentage of Precipitation Anomaly and Surface Humid Index. Acta Geogr. Sin. 2003, 58, 117-124.

19. Zuo, D.; Hou, W.; Wu, H.; Yan, P.; Zhang, Q. Feasibility of Calculating Standardized Precipitation Index with Short-Term Precipitation Data in China. Atmosphere 2021, 12, 603. [CrossRef]

20. Tang, H.; Wen, T.; Shi, P.; Qu, S.; Zhao, L.; Li, Q. Analysis of Characteristics of Hydrological and Meteorological Drought Evolution in Southwest China. Water 2021, 13, 1846. [CrossRef]

21. An, Q.; He, H.; Nie, Q.; Cui, Y.; Gao, J.; Wei, C.; Xie, X.; You, J. Spatial and Temporal Variations of Drought in Inner Mongolia, China. Water 2020, 12, 1715. [CrossRef]

22. Yao, J.; Zhao, Y.; Chen, Y.; Yu, X.; Zhang, R. Multi-scale assessments of droughts: A case study in Xinjiang, China. Sci. Total. Environ. 2018, 630, 444-452. [CrossRef] [PubMed]

23. Vicente-Serrano, S.M.; Beguería, S.; López-Moreno, J.I. A Multiscalar Drought Index Sensitive to Global Warming: The Standardized Precipitation Evapotranspiration Index. J. Clim. 2010, 23, 1696-1718. [CrossRef]

24. Tan, C.P.; Yang, J.P.; Li, M. Temporal-Spatial Variation of Drought Indicated by SPI and SPEI in Ningxia Hui Autonomous Region, China. Atmosphere 2015, 6, 1399-1421. [CrossRef]

25. Tirivarombo, S.; Osupile, D.; Eliasson, P. Drought monitoring and analys is: Standardised Precipitation Evapo-transpiration Index (SPEI) and Standardised Precipitation Index (SPI). Phys. Chem. Earth 2018, 106, 1-10. [CrossRef]

26. Cook, B.I.; Smerdon, J.E.; Seager, R.; Coats, S. Global warming and 21st century drying. Clim. Dyn. 2014, 43, 2607-2627. [CrossRef]

27. Thornthwaite, C.W. An Approach toward a Rational Classification of Climate. Geogr. Rev. 1948, 38, 55-94. [CrossRef]

28. Jensen, M.E.; Burman, R.D.; Allen, R.G. Evapotranspiration and Irrigation Water Requirements; American Society of Civil Engineers (ASCE): Reston, VA, USA, 1990.

29. Sheffield, J.; Wood, E.; Roderick, M. Little change in global drought over the past 60 years. Nature 2012, 491, 435-438. [CrossRef]

30. Li, B.; Liang, Z.; Yu, Z.; Acharya, K. Evaluation of drought and wetness episodes in a cold region (Northeast China) since 1898 with different drought indices. Nat. Hazards 2013, 71, 2063-2085. [CrossRef]

31. Bae, S.; Lee, S.-H.; Yoo, S.-H.; Kim, T. Analysis of Drought Intensity and Trends Using the Modified SPEI in South Korea from 1981 to 2010. Water 2018, 10, 327. [CrossRef]

32. Wei, S.; Liu, J.; Li, T.; Wang, X.; Peng, A.; Chen, C. Effect of High-Temperature Events When Heading into the Maturity Period on Summer Maize (Zea mays L.) Yield in the Huang-Huai-Hai Region, China. Atmosphere 2020, 11, 1291. [CrossRef]

33. Liu, D.L.; Zuo, H. Statistical downscaling of daily climate variables for climate change impact assessment over New South Wales, Australia. Clim. Chang. 2012, 115, 629-666. [CrossRef]

34. Moss, R.H.; Edmonds, J.A.; Hibbard, K.A.; Manning, M.R.; Rose, S.K.; van Vuuren, D.P.; Carter, T.R.; Emori, S.; Kainuma, M.; Kram, T.; et al. The next generation of scenarios for climate change research and assessment. Nature 2010, 463, 747-756. [CrossRef]

35. Van Vuuren, D.P.; Stehfest, E.; den Elzen, M.G.J.; Kram, T.; Van Vliet, J.; Deetman, S.; Isaac, M.; Goldewijk, K.K.; Hof, A.; Beltran, A.M.; et al. RCP2.6: Exploring the possibility to keep global mean temperature increase below $2{ }^{\circ} \mathrm{C}$. Clim. Chang. 2011, 109, 95-116. [CrossRef]

36. RCP Database. RCP Database Version 1.0 Hosted at IIASA. 2009. Available online: http://www.iiasa.ac.at/web-apps/tnt/RcpDb (accessed on 23 November 2009).

37. Allen, R.G.; Pereira, L.S.; Raes, D.; Smith, M. Crop Evapotranspiration: Guidelines for computing crop water requirements. Food Agri. Org. United Nations Irrig. Drain. Pap. 1998, 56, 300.

38. Xu, S.; Yu, Z.; Yang, C.; Ji, X.; Zhang, K. Trends in evapotranspiration and their responses to climate change and vegetation greening over the upper reaches of the Yellow River Basin. Agric. For. Meteorol. 2018, 263, 118-129. [CrossRef]

39. Wang, W.; Chen, X.; Shi, P.; Van Gelder PH AJ, M.; Corzo, G. Extreme precipitation and extreme streamfow in the Dongjiang River Basin in southern China. Hydrol. Earth Syst. Sci. Dis. 2008, 12, 207-221. [CrossRef]

40. Li, C.; Wu, P.; Li, X.; Zhou, T.; Sun, S.; Wang, Y.; Luan, X.; Yu, X. Spatial and temporal evolution of climatic factors and its impacts on potential evapotranspiration in Loess Plateau of Northern Shaanxi, China. Sci. Total. Environ. 2017, 589, 165-172. [CrossRef]

41. Li, Z.; Zheng, F.-L.; Liu, W. Spatiotemporal characteristics of reference evapotranspiration during 1961-2009 and its projected changes during 2011-2099 on the Loess Plateau of China. Agric. For. Meteorol. 2012, 154-155, 147-155. [CrossRef]

42. Liu, Y.; Yao, X.; Wang, Q.; Yu, J.; Jiang, Q.; Jiang, W.; Li, L. Differences in Reference Evapotranspiration Variation and ClimateDriven Patterns in Different Altitudes of the Qinghai-Tibet Plateau (1961-2017). Water 2021, 13, 1749. [CrossRef]

43. Wang, Z.; Ye, A.; Wang, L.; Liu, K.; Cheng, L. Spatial and temporal characteristics of reference evapotranspiration and its climatic driving factors over China from 1979-2015. Agric. Water Manag. 2019, 213, 1096-1108. [CrossRef]

44. Zhang, D.; Liu, X.; Hong, H. Assessing the effect of climate change on reference evapotranspiration in China. Stoch. Environ. Res. Risk Assess. 2013, 27, 1871-1881. [CrossRef]

45. Gao, X.; Zhao, Q.; Zhao, X.; Wu, P.; Pan, W.; Gao, X.; Sun, M. Temporal and spatial evolution of the standardized precipitation evapotranspiration index (SPEI) in the Loess Plateau under climate change from 2001 to 2050. Sci. Total Environ. 2017, 595, 191-200. [CrossRef] 
46. Roderick, M.L.; Farquhar, G.D. The cause of decreased pan evaporation over the past 50 years. Science 2002, $298,1410-1411$. [CrossRef]

47. Zhao, J.; Liu, Q.; Lu, H.; Wang, Z.; Zhang, K.; Wang, P. Future droughts in China using the standardized precipitation evapotranspiration index (SPEI) under multi-spatial scales. Nat. Hazards 2021, 109, 615-636. [CrossRef]

48. Wang, L.; Chen, W.; Zhou, W. Assessment of future drought in Southwest China based on CMIP5 multimodel projections. Adv. Atmos. Sci. 2014, 31, 1035-1050. [CrossRef]

49. Li, X.X.; Hui, J.U.; Sarah, G.; Yan, C.R.; Batchelor, W.D.; Qin, L.I.U. Spatiotemporal variation of drought characteristics in the Huang-Huai-Hai Plain, China under the climate change scenario. J. Integr. Agric. 2017, 16, 2308-2322. [CrossRef] 